\title{
Desinfecção de água de chuva por radiação ultravioleta
}

\section{Disinfection of rainwater by ultraviolet radiation}

\begin{abstract}
Elisabeth Wisbeck
Engenheira Química pela Universidade Regional de Blumenau (Furb). Doutora em Engenharia Química pela Universidade Federal de Santa Catarina (UFSC). Professora do Mestrado em Engenharia de Processos da Universidade da Região de Joinville (Univille) e dos Departamentos de Engenharia Ambiental e Engenharia Química
\end{abstract}

\section{Edgar K Sandri}

Engenheiro Civil pela Universidade de Mogi das Cruzes (UMC). Mestre em Engenharia de Processos pela Univille

\section{Andrea L M Soares}

Engenheira Química pela Univille

\section{Sandra H W Medeiros}

Engenheira Química pela FURB. Doutora em Engenharia Química pela UFSC. Professora do Mestrado em Engenharia de Processos da Univille e dos Departamentos de Engenharia Ambiental e Engenharia Química da Univille

\section{Resumo}

O objetivo deste trabalho foi avaliar o tratamento de água de chuva, de duas regiões industriais de Joinville (SC), por radiação ultravioleta. O reator operou em processo contínuo, de modo que cada partícula permanecesse sob radiação por 60 segundos. As amostras de água foram analisadas em termos de coliformes totais, coliformes termotolerantes e bactérias heterotróficas antes do tratamento por ultravioleta, após o tratamento e após tratadas e armazenadas por 24, 48 e 72 horas. Verificou-se a eficiência da desinfecção de água de chuva direta e de telhado por radiação ultravioleta com a inativação de 100\% dos coliformes totais e dos coliformes termotolerantes e o não recrescimento desses micro-organismos em amostras tratadas e estocados por até 72 horas, no entanto, bactérias heterotróficas persistiram e foram identificadas após 24, 48 e 72 horas ao tratamento.

Palavras-chave: água de chuva; radiação ultravioleta; desinfecção.

\section{Abstract}

The objective of this study was to evaluate the treatment of rainwater in two industrial regions in Joinville (SC, Brazil) by ultraviolet radiation. The reactor was operating in continuous process with each particle remaining under radiation for 60 seconds. The samples were evaluated in terms of total coliforms, fecal coliform and heterotrophic bacteria prior to ultraviolet treatment, after treatment and further treated and stored for 24,48 and 72 hours. The efficiency of disinfection of direct rainwater and that collected from roofing by ultraviolet radiation was verified with $100 \%$ inactivation of total coliforms and fecal coliform and these microorganisms did not reappear in samples treated and stored for up to 72 hours, however, heterotrophic bacteria persisted and were identified after 24,48 and 72 hours of treatment.

Keywords: rainwater; ultraviolet radiation; disinfection.

\section{Introdução}

Uma questão que traz preocupações nos sistemas de aproveitamento de águas pluviais é a qualidade da água obtida, principalmente se for para atender a todas as necessidades domésticas. De um modo geral, a água pluvial, devido ao processo de destilação natural que sofre, pode ser considerada de boa qualidade. Entretanto, dependendo da região, a chuva pode apresentar poluentes, principalmente em regiões próximas aos grandes centros urbanos ou a áreas bastante industrializadas (SILVA e DOMINGOS, 2007).
Apesar do cloro $\left(\mathrm{Cl}_{2}\right)$ ser o desinfetante químico mais utilizado na desinfecção para produção de água potável, várias pesquisas foram realizadas, buscando consolidar tecnologias e parâmetros que viabilizem o uso da radiação ultravioleta (UV), visando a uma maior adequação e otimização do processo para sua utilização eficaz no atendimento à população, tanto no âmbito industrial como no de saúde pública (AGUIAR et al., 2002; BILOTTA e DANIEL, 2006; LOBO; COSTA; WISBECK, 2009; SÁ SILVA et al., 2003; SOUZA; SARTORI; DANIEL, 2000; WALKING-RIBEIRO et al., 2008). 
Um equipamento de desinfecção de água por radiação ultravioleta, para ser eficiente, necessita garantir uma dose letal. Segundo Edstrom Industries Inc. (2003), a dose letal depende de uma série de condições físico-químicas da água, como por exemplo, grau de turbidez ( $<5 \mathrm{NTU})$, sólidos em suspensão $\left(<10 \mathrm{mg} \cdot \mathrm{L}^{-1}\right)$, concentração de ferro $\left(<0,3 \mathrm{mg} \cdot \mathrm{L}^{-1}\right)$ e dureza $\left(<120 \mathrm{mg} \cdot \mathrm{L}^{-1}\right)$.

A portaria n. ${ }^{\circ} 518$ do Ministério da Saúde (BRASIL, 2004) exige que a água potável deva estar ausente de coliformes totais, coliformes termotolerantes e determina um limite de 500 UFC. $\mathrm{mL}^{-1}$ de bactérias heterotróficas em 20\% das amostras mensais analisadas nos sistemas de distribuição de águas destinadas a consumo humano.

O grupo dos coliformes totais inclui todas as bactérias na forma de bastonetes Gram-negativos, aeróbios ou anaeróbios, capazes de fermentar a lactose com produção de gás e avalia as condições higiênicas da água. A detecção de coliformes termotolerantes indica contaminação por fezes e possível presença de organismos causadores de doenças gastrintestinais (COMPANHIA DE TECNOlOGIA DE SANEAMENTO AMBIENTAL, 1993). As bactérias heterotróficas podem estar em todo lugar, desde o solo até o ar, daí sua possível presença na água de chuva. A maioria das bactérias heterotróficas, geralmente, não é patógena. Entretanto alguns membros desse grupo, incluindo Legionella spp., Micobacterium spp., Pseudomonas spp., Aeromonas spp., podem ser patógenos oportunistas que estão naturalmente presentes no ambiente (QUIROZ, 2002).

Assim, este trabalho objetivou avaliar o tratamento de água de chuva de precipitação direta e de drenagem de telhados de duas regiões industriais de Joinville (SC), por radiação ultravioleta (UV). Para tanto, realizou-se o tratamento das amostras de água de chuva durante 60 segundos e verificou-se se a dose de radiação UV foi letal aos micro-organismos por meio da análise logo após o tratamento e 24, 48 e 72 horas após o tratamento. Ainda, os parâmetros dureza, ferro, turbidez, sólidos totais e $\mathrm{pH}$, que influenciam no processo de desinfecção por radiação UV, foram avaliados.

\section{Material e métodos}

As coletas foram realizadas, simultaneamente, em duas regiões industriais da cidade de Joinville, no bairro Bom Retiro e na região do Boa Vista. Os pontos de coleta foram escolhidos em função dos possíveis particulados carreados na precipitação, conforme estudo do clima urbano feito por Hackenberg (1992).

As amostras foram coletadas por precipitação direta e por drenagem de telhados de cimento amianto entre $1^{\circ}$ de agosto e 16 de novembro de 2008, todas em período de chuva com características distintas, como tempo seco, úmido, com trovoadas e ventos, frio e calor. O telhado de cimento amianto foi escolhido por ser o mais usado devido ao seu baixo custo e menor exigência de estrutura, sendo a opção de grande parte da população brasileira (LEE, 2000).
As coletas do bairro Bom Retiro aconteceram no Campus Universitário da Universidade da Região de Joinville (Univille), que é margeado por grandes indústrias. Na região do Boa Vista, as coletas foram no quintal de uma residência a cerca de $20 \mathrm{~m}$ de uma fundição. Todas as coletas foram realizadas após os 10 primeiros minutos de precipitação (JAQUES, 2005). As coletas de água de chuva direta foram realizadas em recipientes plásticos de diâmetro de $70 \mathrm{~cm}$, a $1 \mathrm{~m}$ do solo. As coletas de água de chuva de telhado foram captadas de calhas de PVC, com auxílio de uma peneira para filtrar os sólidos grossos, com um funil conectado à entrada de um frasco plástico.

Todos os recipientes utilizados nas coletas foram previamente higienizados com álcool $70 \%$ e lavados com a própria água da chuva proveniente do início da coleta. Imediatamente após as coletas, as amostras foram analisadas em termos de dureza, ferro, turbidez, sólidos totais, $\mathrm{pH}$, coliformes totais, coliformes termotolerantes, bactérias heterotróficas e encaminhadas para o tratamento por radiação UV.

$\mathrm{O}$ reator passou por um processo de higienização antes de ser utilizado. Foi lavado três vezes com água de torneira e, após, completou-se o reator, novamente, com água de torneira e deixou-se por 5 minutos à luz UV ligada. Essa água permaneceu até o início dos tratamentos da água de chuva.

As amostras de água foram tratadas por UV em processo contínuo, numa vazão de 0,04 L.s ${ }^{-1}$, obtida por gravidade, calculada para uma exposição das amostras por 60 segundos à radiação UV (LOBO; COSTA; WISBECK, 2009). Nessa condição, Lobo (2008) relata que as células de Escherichia coli recebem uma dose de radiação de 9,2 $\mathrm{mWs}_{\mathrm{cm}} \mathrm{cm}^{2}$, determinada por bioensaios. Esse valor é superior ao sugerido por Wright e Cairns (1998) para inativar 99\% de células viáveis de E. coli $(6,6$ mWs.cm²-2).

Uma vez que o reator, ao ser higienizado, estava preenchido com 2,5 L de água de torneira, após o escoamento de cerca de 3 L, na vazão de 0,04 L.s $\mathrm{s}^{-1}, 400 \mathrm{~mL}$ de amostra de água de chuva foram armazenados em frascos transparentes de Duran de $250 \mathrm{~mL}$, contendo $100 \mathrm{~mL}$ de amostra por frasco, previamente esterilizados. Um frasco foi utilizado para análise de coliformes totais, coliformes termotolerantes e bactérias heterotróficas, imediatamente após o tratamento. Os demais frascos foram armazenados em temperatura e luminosidade ambiente por 24, 48 e 72 horas, para análise de coliformes totais, coliformes termotolerantes e bactérias heterotróficas, após o tratamento. Esse procedimento foi adotado para a verificação da inativação dos microorganismos (dose letal) por até 72 horas de estocagem.

O reator utilizado na desinfecção era de aço inoxidável, modelo UV-0136-02, com os seguintes dados do fabricante: volume de 2,5 L acoplado com uma lâmpada UV de $30 \mathrm{~W}$ (submersa). Comprimento e diâmetro da câmara de 90 e 7,6 cm, respectivamente. Diâmetro das conexões de entrada e saída: $3,8 \mathrm{~cm}$.

Coliformes totais e coliformes termotolerantes nas amostras de água, foram detectados pelo método Colilert, sendo seus valores expressos em NMP.100 $\mathrm{mL}^{-1}$ (número mais provável.100 $\mathrm{mL}^{-1}$ ) (COMPANHIA DE TECNOLOGIA DE SANEAMENTO AMBIENTAL, 
1993). Para a análise de bactérias heterotróficas, foi utilizado o método pour plate com meio PCA (Plate Count Agar) e o resultado expresso em unidades formadoras de colônia (UFC). $\mathrm{mL}^{-1}$ (Equação 1). Todo o material utilizado nessas análises foi previamente esterilizado a $121^{\circ} \mathrm{C}$ por 15 minutos.

$\frac{\mathrm{UFC}}{\mathrm{mL}}=\frac{\mathrm{Nc} \times \mathrm{d}}{\mathrm{V}}$ Equação 1

Onde:

Nc: número de colônias na placa (UFC);

d: diluição da amostra na placa;

$\mathrm{V}$ : volume de amostra inoculado $(\mathrm{mL})$.

As análises de turbidez, sólidos totais, dureza e Fe foram realizadas seguindo o Standard Methods for the Examination of Water and Wastewater (AMERICAN PUBLIC HEALTH ASSOCIATION, 2005). Os valores de $\mathrm{pH}$ foram medidos em $\mathrm{pHmetro}$ de bancada imediatamente após as coletas.

\section{Resultados e discussão}

Na Figura 1, são apresentados os valores médios de coliformes totais, coliformes termotolerantes e bactérias heterotróficas na entrada e na saída do reator e após 24, 48 e 72 horas ao tratamento por radiação UV de amostras de chuva direta e de telhado, respectivamente, nos dois pontos de coleta.

Fica evidente que as amostras de chuva direta (Figura 1A), além de serem menos contaminadas em relação às amostras de chuva provenientes de telhados (Figura 1B), nas do bairro Bom Retiro foram encontrados os menores valores de coliformes totais, coliformes termotolerantes e bactérias heterotróficas. Observa-se, facilmente que, imediatamente após o tratamento por radiação UV (saída do reator), não foi detectada a presença de nenhuma das bactérias avaliadas e que, após o armazenamento por 24, 48 e 72 horas, apenas bactérias heterotróficas estavam presentes.

Observando-se a Figura 1B, verificam-se valores de bactérias heterotróficas superiores a $500 \mathrm{UFC}$. $\mathrm{mL}^{-1}$ na entrada do reator em amostras de água proveniente de telhado e também que, logo após 24 horas de armazenamento, esses valores já ultrapassavam 500 UFC.mL ${ }^{-1}$. Já nas amostras de chuva direta (Figura 1A), além das bactérias heterotróficas estarem em valores menores que $100 \mathrm{UFC} \cdot \mathrm{mL}^{-1}$ na entrada do reator, após 24 horas estocadas não chegaram a ultrapassar 500 UFC. $\mathrm{mL}^{-1}$, o que aconteceu somente após 48 horas de armazenamento. Isso mostra que a quantidade inicial de bactérias heterotróficas influencia a eficiência da desinfecção por radiação UV, nas condições utilizadas neste trabalho.

Segundo Leclerc e Moreau (2002), alguns autores estão pesquisando se essa multiplicação das bactérias heterotróficas na água é devida à reativação de um grande número de células dormentes


Figura 1 - Valores médios \pm desvio padrão de coliformes totais (NMP.100 $\mathrm{mL}^{-1}$ ), coliformes termotolerantes (NMP.100 $\mathrm{mL}^{-1}$ ) e bactérias heterotróficas (UFC. $\mathrm{mL}^{-1}$ ) obtidos em amostras de chuva direta (A) proveniente de telhados (B) no bairro Bom Retiro e na região do Boa Vista (entrada do reator), em amostras tratadas por radiação UV (saída do reator) e armazenadas por 24, 48 e 72 horas após o tratamento por radiação UV.

presentes na água, ou se ela é resultado da divisão celular e multiplicação de poucas células viáveis inicialmente presentes, mas ainda não chegaram a alguma conclusão.

O aparecimento de bactérias heterotróficas 24 horas após o tratamento por UV nas amostras de chuva direta, no entanto, é intrigante. A Figura 1A mostra o valor médio de bactérias heterotróficas em UFC. $\mathrm{mL}^{-1}$, porém, apenas a chuva de uma coleta, na região do Boa Vista, confirmou a presença de bactérias heterotróficas antes do tratamento por UV, nas demais coletas, estas não foram identificadas. Assim, para justificar o aparecimento dessas bactérias, após o tratamento, uma possibilidade é de que elas estivessem, inicialmente, em muito pouca quantidade, daí a não identificação, e quando armazenadas e guardadas em temperatura favorável, elas se desenvolveram. No entanto, fica a dúvida sobre qual fonte de carbono estaria sendo utilizada para seu desenvolvimento, sendo que tal fonte poderia estar nos sólidos totais e estes variaram de 0 a 15 mg..-1 
nas amostras de chuva direta. Outra possibilidade é a de que elas já estivessem em grande quantidade inicialmente, porém, não sendo identificadas por estarem em estado de latência e por sofreram reativação após o período de estocagem (LECLERC; MOREAU, 2002). De qualquer maneira, para essas duas possibilidades, pode-se dizer que a radiação ultravioleta não foi letal a essas bactérias, que podem ter sido fotorreativadas.

Ritter e Tondo (2009) avaliaram em termos de bactérias heterotróficas, água mineral natural tanto do poço quanto do produto final envasado de uma indústria da grande Porto Alegre (RS). As contagens de bactérias heterotróficas encontradas nos garrafões de 20 L foram maiores $\left(1,5 \times 10^{3}\right.$ UFC. $\left.\mathrm{mL}^{-1}\right)$ que as contagens da água do poço $\left(1,1 \times 10^{3}\right.$ UFC. $\left.\mathrm{mL}^{-1}\right)$ realizadas durante 5 dias de coleta. Os autores sugerem que tal aumento microbiano pode ser justificado pela contaminação devido às diferentes etapas de processamento da água mineral ou pela multiplicação bacteriana dentro das bombonas. Jeena et al. (2006) relatam, ainda, que as contagens microbianas podem aumentar nos primeiros dias de envase, diminuindo nas semanas subsequentes até atingirem uma estabilização.

Verifica-se, de acordo com o reportado na literatura, a preocupação em avaliar a presença de bactérias heterotróficas em água mineral, mesmo porque estudos relatam a resistência a antibióticos de vários desses organismos isolados (MESSI; GUERRIERI; BONDI, 2005). No entanto, segundo Fricker (2003), não existe estudo relacionando doenças de veiculação hídrica com o consumo de águas minerais.

A preocupação com a presença de bactérias heterotróficas vai além de águas minerais. Carter et al. (2000) avaliaram a qualidade da água desde a estação de tratamento, passando por um tanque de armazenamento e uma estação de bombeamento, até uma residência particular de Milford, Ohio, nos Estados Unidos. Verificaram que, da estação de tratamento até a estação de bombeamento, houve um aumento em torno de $1.500 \%$ de bactérias heterotróficas. Da estação de bombeamento até a residência particular, a contagem de bactérias heterotróficas reduziu cerca de $75 \%$. No entanto, nenhuma contagem ultrapassou 500 UFC. $\mathrm{mL}^{-1}$.

Moruzzi e Murakami (2009), ao investigarem o efeito do tempo de armazenamento na qualidade de água pluvial destinada a fins não potáveis, em um sistema experimental de captação e armazenamento de água pluvial após passagem por telhado em Ipeúna (SP), verificaram que as bactérias heterotróficas foram resistentes à ação do tempo de armazenamento, indicando a importância da manutenção do residual de cloro na água pluvial armazenada.

Sabe-se ainda que a desinfecção por radiação UV pode sofrer interferência dos parâmetros dureza, ferro, turbidez, sólidos totais e pH. Segundo a Edstrom Industries Inc. (2003) para uma maior eficiência no tratamento de água por radiação UV, esta deve apresentar no máximo um valor de dureza de $120 \mathrm{mg} \cdot \mathrm{L}^{-1}$, ferro de 0,3 mg. $\mathrm{L}^{-1}$, turbidez de $5 \mathrm{NTU}$, sólidos suspensos de $10 \mathrm{mg} . \mathrm{L}^{-1}$ e pH entre 6,5 e 9,5. As partículas existentes na água dificultam a incidência da luz UV sobre os micro-organismos (SOUZA; SARTORI; DANIEL, 2000). Como o valor de sólidos suspensos não foi avaliado nas amostras, a interferência de sólidos, neste trabalho, foi feito em relação aos sólidos totais, uma vez que este pode ser subdividido em sólidos em suspensão e em sólidos dissolvidos (BRASIL, 2006).

Na Tabela 1 estão apresentados os valores médios e o desvio padrão dos parâmetros dureza, ferro, turbidez, sólidos totais e pH das amostras de água coletadas no bairro Bom Retiro e na região do Boa Vista, por precipitação direta e por drenagem de telhados.

Em relação à dureza e ao ferro, todas as amostras avaliadas apresentaram valores médios dentro do recomendado: 120 e 0,3 mg. $\mathrm{L}^{-1}$, respectivamente. Ressalta-se, no entanto, que os valores de dureza e ferro das amostras provenientes de telhados são mais elevados.

Apesar dos valores médios de turbidez estarem de acordo com o recomendado (5 NTU), a amostragem do dia 14 de abril de 2009 apresentou valores acima de $5 \mathrm{NTU}$, tanto para a chuva direta quanto de telhado. Nessa ocasião, ocorreu o período mais seco anterior à coleta, sendo que praticamente não choveu nos 8 dias anteriores, e as chuvas acumuladas resultaram apenas $2,2 \mathrm{~mm}$, promovendo o acúmulo de poluentes e partículas na atmosfera.

A influência da turbidez foi avaliada no trabalho de Souza; Sartori e Daniel (2000) ao realizar experimentos de desinfecção de água por UV contendo a bactéria E. coli em concentrações conhecidas e observaram a influência da turbidez na inativação, pois, nos experimentos utilizando água com turbidez de 2 NTU, 99,99\% de E. coli foram inativados em 20 segundos. Quando a turbidez foi aumentada para 50 NTU, esse tempo aumentou para 120 segundos, com uma inativação de 99,97\%. Neste trabalho, tanto para coliformes totais como para coliformes termotolerantes, apesar

Tabela 1 - Valores médios _desvio padrão de dureza, ferro, turbidez, sólidos totais e pH das águas de chuva coletadas no bairro Bom Retiro e na região do Boa Vista de forma direta e proveniente de telhados

\begin{tabular}{|c|c|c|c|c|}
\hline \multirow[t]{2}{*}{ Parâmetros } & \multicolumn{2}{|c|}{$\begin{array}{c}\text { Coleta direta } \\
\text { Média } \pm \text { desvio padrão }\end{array}$} & \multicolumn{2}{|c|}{$\begin{array}{l}\text { Coleta de telhado } \\
\text { Média } \pm \text { desvio padrão }\end{array}$} \\
\hline & Bom Retiro & Boa Vista & Bom Retiro & Boa Vista \\
\hline Dureza (mg. $\left.\mathrm{L}^{-1}\right)$ & $1,30 \pm 1,56$ & $0,87 \pm 0,25$ & $17,20 \pm 5,36$ & $21,75 \pm 6,85$ \\
\hline Ferro (mg. $\left.\mathrm{L}^{-1}\right)$ & $0,02 \pm 0,017$ & $0,03 \pm 0,022$ & $0,054 \pm 0,056$ & $0,065 \pm 0,017$ \\
\hline Turbidez (NTU) & $2,87 \pm 2,54$ & $2,31 \pm 0,70$ & $4,35 \pm 3,40$ & $2,99 \pm 0,64$ \\
\hline Sólidos totais (mg. $\left.\mathrm{L}^{-1}\right)$ & $14,0 \pm 20,8$ & $6,75 \pm 7,89$ & $39,4 \pm 21,03$ & $49,25 \pm 22,56$ \\
\hline $\mathrm{pH}$ & $6,06 \pm 0,73$ & $6,93 \pm 0,88$ & $6,24 \pm 0,25$ & $6,33 \pm 0,29$ \\
\hline
\end{tabular}


dos valores de turbidez mais elevados na coleta do dia 14 de abril de 2009, estes não influenciaram a eficiência da desinfecção por radiação UV contra tais micro-organismos. Já, para as bactérias heterotróficas, não se pode afirmar que a turbidez teve influência negativa no processo de desinfecção por UV, pois, nas demais coletas, com valores adequados de turbidez, percebeu-se também recrescimento dessas bactérias.

Com respeito aos sólidos totais, as amostras de chuva de telhado apresentaram valores superior a $10 \mathrm{mg} \cdot \mathrm{L}^{-1}$. Nas amostras de chuva direta, as do Bom Retiro ficaram acima do recomendado. Na região do Boa Vista, apesar da maioria das amostras apresentarem valores de concentração de sólidos totais abaixo do limite de detecção, até mesmo nessas amostras foi identificada a presença de bactérias heterotróficas, 24 horas após o tratamento por UV.

Nagel-Hassemer; Lapolli e Oliveira (2002) verificaram a viabilidade da radiação UV na desinfecção de efluentes tanto para coliformes totais como termotolerantes, com reduções de 99,99\%, mesmo em amostras com valores altos de sólidos totais ( $\left.80 \mathrm{mg} . \mathrm{L}^{-1}\right)$ e de turbidez (90 NTU).

Quando Lobo; Costa e Wisbeck (2009) avaliaram a desinfecção de água por UV com concentrações conhecidas de E. coli, verificando que, para uma concentração de $100 \mathrm{mg} \cdot \mathrm{L}^{-1}$ de sólidos em suspensão, concentração 10 vezes maior que a máxima recomendada, com um tempo de exposição de 30 segundos, alcançou 89,75\% de inativação das células enquanto que para a concentração de $10 \mathrm{mg} \cdot \mathrm{L}^{-1}$ de sólidos em suspensão, essa inativação foi de 99,62\%.

Os valores de $\mathrm{pH}$ nas amostragens variaram entre 4,7 e 6,63 na precipitação direta, e 6,0 e 6,75 na drenagem de telhados, sendo valores próximos ao mínimo recomendado pela Endstrom Industries Inc. (2003).

Independentemente dos valores de dureza, ferro, turbidez, sólidos totais e pH das amostras de água de chuva, o tratamento por radiação UV nas condições utilizadas no presente trabalho, foi eficiente apenas para coliformes totais e coliformes termotolerantes, e não para bactérias heterotróficas.

\section{Conclusões}

A eficiência da desinfecção de água de chuva direta e de telhado por radiação UV foi verificada com a inativação de 100\% dos coliformes totais e coliformes termotolerantes e o não recrescimento desses micro-organismos em amostras tratadas e estocadas por até 72 horas.

Este trabalho, mesmo apresentanto bons resultados de desinfecção com respeito a coliformes totais e coliformes termotolerantes, deixou claro que o processo necessita de mais investigação para promover uma desinfecção a ponto de tornar a água de chuva potável, em termos bacteriológicos, uma vez que em todas as amostras de água armazenadas após o tratamento por radiação UV, verificou-se a presença de bactérias heterotróficas.

\section{Referências}

AGUIAR, A.M.S.; BRITO, L.L.A.; FERNANDES NETO, M.L. et al. Avaliação do emprego da radiação ultravioleta na desinfecção de águas com turbidez e cor moderadas. Engenharia Sanitária e Ambiental, v. 7 , p. 37-47, 2002

AMERICAN PUBLIC HEALTH ASSOCIATION (APHA). Standard Methods for the Examination of Water and Wastewater. 21. ed. Washington DC, 2005.

BILOTTA, P.; DANIEL, L.A. Ozônio e radiação UV na inativação de indicadores patogênicos em esgoto sanitário: análise comparativa. Minerva, v. 3, n. 2, p. 199-207, 2006.

BRASIL. Ministério da Saúde, Secretaria de Vigilância em Saúde. Vigilância e controle da qualidade da água para consumo humano. Série B. Textos Básicos de Saúde. Brasília, DF: Ministério da Saúde, 2006.

Ministério da Saúde. Portaria $n^{\circ}$ 518, de 25 de março de 2004. Norma de qualidade da água de consumo humano. Brasília, DF: Ministério da Saúde, 2004. p. 266.

CARTER, J.T.; RICE, E.W.; BUCHBERGER, S.G. et al. Relationships between levels of heterotrophic bacteria and water quality parameters in a drinking water distribution system. Water Research, v. 34, n. 5, p. 1495-1502, 2002.
COMPANHIA DE TECNOLOGIA DE SANEAMENTO AMBIENTAL, CETESB. Coliformes totais e fecais - determinação pela técnica de tubos múltiplos. Apostila técnica, 1993.

EDSTROM INDUSTRIES INC. Ultraviolet disinfection, p. 3-8, 2003. Cited 2009, May. Available from: http://www.edstrom.com/DocLib/MI4178.pdf

FRICKER. C.R. The presence of bacteria in water after regrowth. In: BARTRAM, J.; COTRUVO, J.; EXNER, M. et al. (Eds). Heterotrophic Plate Counts and Drinking-water Safety. World Health Organization (WHO). London, UK: IWA Publishing, 2003. p. 49-60.

HACKENBERG, A.M. O clima urbano numa cidade estuária de fundo de baia - Joinville/SC. 145p. Dissertação (Mestrado em Arquitetura) Universidade de São Paulo (USP), São Carlos, 1992.

JAQUES, R.C. Qualidade da água de chuva no município de Florianópolis e sua potencialidade para aproveitamento em edificações. 102p. Dissertação (Mestrado em Engenharia Ambiental) - Universidade Federal de Santa Catarina, Florianópolis, 2005.

JEENA, M.I.; DEEPA, P.; MUJEEB RAHIMAN, K.M. et al. Risk assessment of heterotrophic bacteria from bottled drinking water sold in Indian markets. International Journal of Hygiene and Environmental Health, v. 209, p. 191-196, 2006. 
LECLERC, H.; MOREAU, A. Microbiological safety of natural mineral water. FEMS Microbiology Reviews, v. 26, p. 207-222, 2002.

LEE, A. O custo das alternativas de substituição do telhado de cimento amianto. São Paulo, Escola Politécnica da Universidade de São Paulo. 12p. 2000. Disponível em: <http://www.web-resol.org/textos/Telhados de cimento amianto.pdf $>$. Acesso em: ago. 2010.

LOBO, M.G. Avaliação da desinfecção de água por reator utilizado radiação ultravioleta. 84p. Dissertação (Mestrado em Engenharia de Processos) - Universidade da Região de Joinville, Joinville, 2008.

LOBO, M.G.; COSTA, B.P.; WISBECK, E. Avaliação da desinfecção de água em reator utilizando radiação ultravioleta. Revista de Ciências Ambientais, v. 3, n. 1, p. 21-36, 2009.

MESSI, P.; GUERRIERI, E.; BONDI, M. Antibiotic resistance and antibacterial activity in heterotrophic bacteria of mineral water origin. Science of the Total Environment, v. 346, p. 213-219, 2005.

MORUZZI, R.B.; MURAKAMI, M.F. Variação temporal da qualidade da água armazenada para fins de aproveitamento. Engenharia Ambiental, v. 6, n. 3, p. 243-254, 2009

NAGEL-HASSEMER, M.E.; LAPOLLI, F.R.; OLIVEIRA, E.C.M. Desinfecção e valorização de efluentes sanitários através da radiação ultravioleta. In: XXVIII CONGRESO INTERAMERICANO DE INGENIERÍA SANITARIA Y AMBIENTAL, Anais... México, 2002.
QUIROZ, C.C. Água embotellada y su calidad bacteriológica. Água Latinoamérica, p. 38-39, 2002.

RITTER, A.C.; TONDO, E.C. Avaliação microbiológica de água mineral natural e de tampas plásticas utilizadas em uma indùstria da Grande Porto Alegre/RS. Alimentos e Nutrição, v. 20, n. 2, p. 203-208, 2009.

SÁ SILVA, C.A.; ANDRADE, N.J.; SOARES, N.F.F. et al. Evaluation of ultraviolet radiation to control microorganisms adhering to low-density polyethylene films. Brazilian Journal of Microbiology, v. 34, p. 175-178, 2003.

SILVA, V.N.; DOMINGOS, P. Captação e manejo de água de chuva Saúde \& Ambiente em Revista, v. 2, n. 1, p. 68-76, 2007.

SOUZA, J.B.; SARTORI, L.; DANIEL, L.A. Influência da cor e turbidez na desinfecção de águas de abastecimento utilizando-se cloro e radiação ultravioleta. In: XXVII CONGRESSO INTERAMERICANO DE ENGENHARIA SANITÁRIA E AMBIENTAL, Anais... Porto Alegre, 2000. CD ROM.

WALKLING-RIBEIRO, M.; NOCI, F.; CRONIN, D.A. et al. Reduction of Staphylococcus aureus and quality changes in apple juice processed by ultraviolet irradiation, pre-heating and pulsed electric fields. Journal of Food Engineering, v. 89, p. 267-273, 2008.

WRIGTH, H.B.; CAIRNS, W.L. Desinfección de agua por medio de luz ultravioleta In: SIMPOSIO REGIONAL SOBRE CALIDAD DEL AGUA: DESINFECTIÓN EFECTIVA, Anais... Lima, p.1-28, 1998. 